\title{
Exploring Gratitude as an important Life Transforming Strategy
}

\section{Conforte Nathalie Adonon, Benin}

The Peace Gong Benin Coordinator \& President of IRETI ALAFIA

Corresponding author: confonath@gmail.com

Received: 11 Jan., 2019

Revised: 10 Apr., 2019

Accepted: 20 May, 2019

\begin{abstract}
True greatness means that, even if you forget what you've done for others, you never forget what others have done for you and always do your utmost to repay your debts of gratitude.
\end{abstract}

- Josei Toda

Gratitude means feeling thankful or returning the kindness or generosity received from others. As the world finds itself in turmoil and violence of different kinds, each and every individual strive to explore ways to remain happy and live peacefully. What are the different ways in which individuals can imbibe happiness? What are the methods in which individuals live peacefully?

During a series of workshops which the author conducted on nonviolent communication, the participants felt a critical element of nonviolent communication which can help individuals negotiate the complexities of conflicts in their lives and make them happy was the practice of gratitude. Gratitude, the participants felt can change the lives of people as it helped them to appreciate what one had rather than on what one didn't have. They felt gratitude can be life transforming when one starts to feel grateful for everything in their lives, possibly even when they are having problems.

This chapter will look at different dimensions of gratitude, an important element of nonviolent communication which in turn is an essential ingredient for the realization of a culture of peace in our societies. The chapter will explore the perspectives of participants of different workshops conducted by the author on nonviolent communication and try to establish why practicing gratitude transforms one's life.

Keywords: Gratitude, nonviolent communication, gratitude and happiness

"Gratitude is the healthiest of all human emotions. The more you express gratitude for what you have, the more likely you will have even more to express gratitude for."

All ancient philosophies and cultures have given great emphasis on the efficacy of gratitude as a source of inspiration for individuals to contribute towards society. Cicero, in the Roman culture talked of gratitude as the 'mother' of all human feelings. Carman \& Streng (1989) points out on how gratitude is a highly prized human disposition in Jewish, Christian, Buddhist Hindu and Muslim thought. In fact, the consensus among the world's religious and ethical writers is that people are morally obligated to feel and express gratitude in response to received benefits (Emmons \& McCullough, 2003).

When we consider the cosmocentric view of human beings we realize that all life and phenomena in the universe are interconnected. The Chief Seattle of the Suquamish tribe had pointed out way back in 1848, "All things are connected like the blood which unites our family. All things are connected." Eminent ecologist Vandana Shiva says, "We are all members of the Earth family, interconnected 
through the planet's fragile web of life. We all have a duty to live in a manner that protects the Earth's ecological processes, and the rights and welfare of all species and all people."When we recognize that all that is there in the universe are interconnected, it will help us to appreciate the importance of all beings and phenomena in the sustenance of our lives. This definitely is the central idea of gratitude.

The Peace Gong, the global children and youth platform which promotes nonviolent communication underscores on the importance of recognizing debts of gratitude as it is an expression of the highest form of humanism. It also stresses that repaying the gratitude is a symbol of a life of wisdom.

Peace apostle, Daisaku Ikeda talks about the ways to deepen our appreciation, "Thank you is a miraculous expression ... When we speak or hear the words thank you, the armor falls from our hearts, and we communicate on the deepest level." Similarly, Oprah Winfrey notes, "Be thankful for what you have, you'll end up having more. If you concentrate on what you don't have, you will never ever have enough."

Those who have a sense of appreciation and gratitude are loved and trusted by everyone and lead lives of tremendous fulfilment and satisfaction. Based on Nichiren [Daishonin's] teachings, it is clear that the inner radiance of those who embody true gratitude will imbue their lives with indestructible good fortune and benefit throughout the three existences. (Learning From Nichiren's Writings: The Teachings for Victory, vol. 4, p. 28)

Psychologists have defined gratitude as a positive emotional response that we perceive on giving or receiving a benefit from someone (Emmons \& McCullough, 2004). Further, Emmons and McCullough (2003) point out how gratitude has been conceptualized as an emotion, an attitude, a moral virtue, a habit, a personality trait, or a coping response. They talk about researches which suggests that gratitude is a moderately pleasant and activating emotion and how a Gallup (1998) survey of American teens and adults, over 90 per cent of respondents indicated that expressing gratitude helped them to feel "extremely happy" or "somewhat happy.
Emmons and McCullough (2003) explains, "Gratitude is associated with a personal benefit that was not intentionally sought after, deserved, or earned but rather because of the good intentions of another person"

Roy Choudhury ( April, 2019 ) explores the neuroscience of gratitude and how it affects anxiety and grief. She talks about how gratitude is essentially a natural antidepressant. She points out, "The effects of gratitude, when practiced daily can be almost the same as medications. It produces a feeling of long-lasting happiness and contentment, the physiological basis of which lies at the neurotransmitter level."

According to Roy Choudhury, "When we express gratitude and receive the same, our brain releases dopamine and serotonin, the two crucial neurotransmitters responsible for our emotions, and they make us feel 'good'. They enhance our mood immediately, making us feel happy from the inside. By consciously practicing gratitude every day, we can help these neural pathways to strengthen themselves and ultimately create a permanent grateful and positive nature within ourselves."

In the context of the wide framework of the benefits of gratitude, an important element of nonviolent communication, the author conducted a few workshops on nonviolent communication. An important dimension of these workshops was the focus on gratitude. This chapter will examine the perspective of the participants on the benefits of expressing gratitude in our daily lives.

\section{Perspective of Participants}

Gratitude is the secret of life. The essential thing is to thank for everything. He who has learned this knows what it means to live. He has penetrated the profound mystery of life.

\section{- Albert Schweitzer}

Most of the participants felt that by practicing gratitude we can change our life as it is able to shift our focus. They felt it helps us to see positively even in challenging times. Even when something goes wrong, individuals practicing gratitude look 
for the silver-lining in the situation. If they can't find one, they simply state that something good will eventually come out of whatever they're going through.

It was felt that gratitude breathes positivity into whatever we are trying to do. According to the participants, "It's a monumental shift in focus, a new way of seeing things, one that involves a wild-eyed appreciation for the beauty of all things. You move from living in a state of lack, to living in a state of sheer abundance in every possible way."

An important benefit of expressing gratitude is improvement of the quality of life. It was felt that mental health, wellness, our emotional fortitude, spiritual aptitude and even our physical strength all can be strengthened by making it a practice to express gratitude in our daily lives.

The participants felt that gratitude was critical for long-term happiness of individuals and even societies. In this context, Roy Choudhury ( ) points out, "The connection between gratitude and happiness is multi-dimensional. Expressing gratitude not only to others but also to ourselves, induces positive emotions, primarily happiness. By producing feelings of pleasure and contentment, gratitude impacts on our overall health and wellbeing as well." She notes, "Simple practices like maintaining a gratitude journal, complimenting the self, or sending small tokens and thank you notes can make us feel a lot better and enhance our mood immediately."

The participants discussed the efficacy of maintaining a gratitude journal. A gratitude journal is one's personal space to pen down all small and big things in life that one is thankful for. We can maintain it in a diary or in an online notepad. As we sit to express gratitude,we will consciously choose to focus on the good memories and might even recollect some long lost happy moments, the participants felt.

According to Roy Choudhury, "Positive psychology and mental health researchers in the past few decades have established an overwhelming connection between gratitude and good health. Keeping a gratitude journal causes less stress, improves the quality of sleep, and builds emotional awareness. Gratitude is positively correlated to more vitality, energy, and enthusiasm to work harder."

Some of the participants felt by expressing gratitude, we can overcome fear. They observed that gratitude can help us reducing our fears because it's hard to be fearful and grateful at the same time. It was generally felt that when we're grateful for everything we have, including our problems, fear has little place to live in our minds.

According to some of the participants, gratitude helps us to transform our faith by instilling the belief that we not alone and that whatever we are going through, it will pass, and on the other end we will emerge victorious. Expression of gratitude can aid us to accomplish our goals, overcome our obstacles, and become a better person, one who's more sympathetic and even empathetic to the plight of others.

The participants felt gratitude has important relationship with difficulties and individual resilience. Roy Choudhury gives a detailed explanation to this, "Psychologists Shai Davidai and Thomas Gilovich, in one of their papers, called the 'Headwinds/Tailwinds Asymmetry: An Availability Bias in Assessments of Barriers and Blessings' mentioned that we tend to focus more on the obstacles and difficulties of life because they demand some action. We have to fight and overcome them to get back the normal flow of life. On the flip-side, we forget to attend to the better things in life because they are 'already there' and we don't have to do anything to make them stay with us. Practicing gratitude, according to Gilovich, is the best way to remind ourselves of the things that give us the courage to move on in life."

Simple gratitude practices discussed for developing emotional resilience are meditation and breadth control, construction of a gratitude list, and writing gratitude notes. As Gandhi had said, "May the work of your hands be a sign of gratitude and reverence to the human condition," the participants observed that individuals should continuously act to repay their debt of gratitude. 


\section{CONCLUSION}

The practice of gratitude is not in any way a denial of life's difficulties. We live in troubling times, and no doubt you've experienced many challenges, uncertainties, and disappointments in your own life. Rather, gratitude practice is useful because it turns the mind in such a way that it enables you to live into life or, more accurately, to die into life. Having access to the joy and wonderment of life is the antidote to feelings of scarcity and loss. It allows you to meet life's difficulties with an open heart. The understanding you gain from practicing gratitude frees you from being lost or identified with either the negative or the positive aspects of life, letting you simply meet life in each moment as it rises (http://dharmawisdom.org/teachings/articles/ selfless-gratitude)

The important underlying idea that emerged from the workshops was how each individual can change themselves and be catalyst for societal transformation when they learn to express gratitude. Melody Beatties has pertinently said, "Gratitude unlocks the fullness of life. It turns what we have into enough, and more. It turns denial into acceptance, chaos to order, confusion to clarity. It can turn a mean into a feast, a house into a home, a stranger into a friend. Gratitude makes sense of our past, brings peace for today, and creates a vision for tomorrow."

\section{REFERENCES}

Carman, J.B. and Streng, F.J. (Eds.). 1989. Spoken and unspoken thanks: Some comparative soundings. Dallas, TX: Center for World Thanksgiving

Emmons, R.A. and McCullough, M.E. 2003. Counting Blessings Versus Burdens: An Experimental Investigation of Gratitude and Subjective Well-Being in Daily Life; Journal of Personality and Social Psychology, 84(2): 377-389

Emmons, R.A. 2004. The Psychology of Gratitude: An Introduction. In R.A. Emmons \& M.E. McCullough (Eds.), Series in affective science. The psychology of gratitude (pp. 3-16). New York, NY, US: Oxford University Press.

Roy Choudhury, Madhuleena. 2019. The Neuroscience of Gratitude and how it affects Anxiety and Grief; https:// positivepsychology.com/neuroscience-of-gratitude/; retrieved on October 12, 2019. 